\title{
Script concordance test examinations: Student perception and study approaches
}

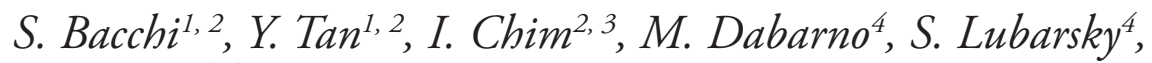 \\ P. Duggan ${ }^{2,3}$
}

\begin{abstract}
Introduction: Script concordance test questions (SCTs) are a style of question that has been developed based upon the script theory of information storage and retrieval. SCTs use script theory to examine a clinical reasoning construct purported to be different from that assessed by multiple-choice questions (MCQs). Evidence regarding the construct validity of SCTs is somewhat limited but generally supportive.
\end{abstract}

Methods: This project involved a content-matched MCQ and SCT practice examination delivered to senior medical students $(\mathrm{n}=211)$ from a single institution, with an accompanying survey regarding educational consequences of SCT and MCQ examinations.

Results: Students' responses regarding how they would prepare for an MCQ examination as compared to an SCT examination differed significantly. These differences included greater focus on textbooks and use of websites for MCQ examination preparation $(p<0.001)$. Students reported that for an SCT examination, they would benefit most from in-person teaching from local consultants involved in the process of SCT generation. Students felt that they would also benefit from further instruction regarding key elements of SCT technique and from opportunities to provide written explanations of their reasoning during the exam.

Conclusions: The results suggest that SCTs have educational consequences different from MCQs. Further research into the educational consequences of SCTs, and how these consequences may differ from other methods of assessment, is warranted.

1 Queen Elizabeth Hospital, Adelaide, South Australia

2 University of Adelaide, Adelaide, South Australia

3 Royal Adelaide Hospital, Adelaide, South Australia

4 McGill University, Montreal, QC, Canada

\section{Correspondence}

Stephen Bacchi

Basic Physician Trainee

Queen Elizabeth Hospital

28 Woodville Rd

Woodville South, SA 5011

Australia

Tel: +61882226000

Email: Stephen.bacchi@sa.gov.au 
Keywords: script concordance test; SCT; multiple choice question; MCQ; consequences.

\section{Background}

Script concordance test questions (SCTs) are a style of question that has been developed based upon the script theory of information storage and retrieval, which is founded upon research in cognitive psychology (Charlin, Boshuizen, Custers, \& Feltovich, 2007). This theory posits that individuals store their knowledge in interconnected knowledge scripts, which, when presented with a real-life scenario, can be retrieved to produce a model that is then used to interpret the given situation. In a medical setting, this script theory takes the form of illness scripts, which represent a clinician's diagnostic and therapeutic approach to a clinical situation (Lubarsky, Dory, Audétat, Custers, \& Charlin, 2015). SCTs are a means of assessing illness scripts and individuals ability to use them in settings of clinical uncertainty (Charlin \& van der Vleuten, 2004). Theoretically, a trainee's illness scripts should grow in depth and complexity through their training, which should be reflected as increasing concordance with a panel of experts and, thus, a higher score on an SCT (Charlin, Roy, Brailovsky, Goulet, \& van der Vleuten, 2000).

SCTs test illness scripts by presenting candidates with a clinically-uncertain stem and then testing their ability to interpret data in light of a suggested possible diagnosis or management option, with results ranging from much less likely/appropriate to much more likely/appropriate (see Table 1 for example SCTs) (Fournier, Demeester, \& Charlin, 2008). An explanation of the theory underlying SCTs and a full explanation of their construction and scoring systems have been reviewed previously (Lubarsky, Dory, Duggan, Gagnon, \& Charlin, 2013). Most commonly, the questions are marked based on the distribution of scores provided by a panel of experts (usually $\geq 10$ experts) (Lubarsky et al., 2013). Variation among answers provided by members of the expert panel results in at least one most preferred answer (the modal answer) and typically one or two options being awarded partial marks. It is this distribution of expert panel answers that adds to the discriminative value of SCTs (Charlin et al., 2006).

SCTs have been supported in terms of their content and internal consistency by multiple studies (Lubarsky, Charlin, Cook, Chalk, \& van der Vleuten, 2011a). However, there is limited validity evidence regarding the acceptability and educational consequences of SCTs (Lubarsky et al., 2011a). Educational consequences of an assessment may be defined as "the impact, beneficial or harmful, of the assessment itself and the decisions and actions that result (e.g., remediation following sub-standard performance)" (Cook, Zendejas, Hamstra, Hatala, \& Brydges, 2014, p. 235). Acceptability of an assessment refers to the perceptions, including beliefs and attitudes, of examinees and examiners towards an assessment method or tool (van der Vleuten, 1996). The two concepts are linked, in that understanding of both the educational consequences of an assessment and the acceptability of an assessment are helpful to determine its potential utility (van der Vleuten, 1996). In a sense, both concepts may be seen to contribute to the critical "consequences" category of validity evidence outlined in the Messick validity framework, in that students may respond to feedback from an assessment differently if they find an assessment unacceptable (Messick, 1989). 
Table 1

Examples of Script Concordance Test Questions (SCTS)

\begin{tabular}{|c|c|c|c|c|c|c|c|}
\hline \multicolumn{8}{|c|}{ Diagnosis SCT } \\
\hline \multirow{2}{*}{$\begin{array}{l}\text { A } 25 \text {-year-old male presents to the GP } \\
\text { with pain in his lower back, left knee and } \\
\text { left ankle. The pain has been present } \\
\text { for the last } 2 \text { months and is limiting his } \\
\text { ability to perform his daily activities. } \\
\text { Paracetamol has not helped to alleviate } \\
\text { the pain. }\end{array}$} & If you were & And then you & \multicolumn{5}{|c|}{ This diagnosis becomes: } \\
\hline & $\begin{array}{l}\text { Disc prolapse } \\
\text { with } \\
\text { radiculopathy }\end{array}$ & $\begin{array}{l}\text { The pain } \\
\text { improves with } \\
\text { exertion }\end{array}$ & $\begin{array}{l}\text { Much less } \\
\text { likely }\end{array}$ & $\begin{array}{l}\text { Slightly less } \\
\text { likely }\end{array}$ & $\begin{array}{l}\text { Neither more } \\
\text { nor less likely }\end{array}$ & $\begin{array}{c}\text { Slightly more } \\
\text { likely }\end{array}$ & $\begin{array}{c}\text { Much more } \\
\text { likely }\end{array}$ \\
\hline \multirow{2}{*}{$\begin{array}{l}\text { A } 25 \text {-year-old female presents to the } \\
\text { GP complaining of excessive sweating } \\
\text { at nighttime over the past month. } \\
\text { During this time, she has also been } \\
\text { feeling tired and has lost } 3 \mathrm{~kg} \text { of weight } \\
\text { unintentionally. She also reports that } \\
\text { she has recently developed a lump in } \\
\text { her neck. }\end{array}$} & $\begin{array}{l}\text { If you were } \\
\text { thinking of: }\end{array}$ & $\begin{array}{l}\text { And then you } \\
\text { find: }\end{array}$ & \multicolumn{5}{|c|}{ This management becomes: } \\
\hline & $\begin{array}{l}\text { Ordering a } \\
\text { lymph node } \\
\text { biopsy }\end{array}$ & $\begin{array}{l}\text { She reports } \\
\text { generalised } \\
\text { pruritus }\end{array}$ & $\begin{array}{l}\text { Much less } \\
\text { appropriate }\end{array}$ & $\begin{array}{l}\text { Slightly less } \\
\text { appropriate }\end{array}$ & $\begin{array}{c}\text { Neither more } \\
\text { nor less } \\
\text { appropriate }\end{array}$ & $\begin{array}{l}\text { Slightly more } \\
\text { appropriate }\end{array}$ & $\begin{array}{l}\text { Much more } \\
\text { appropriate }\end{array}$ \\
\hline \multirow{2}{*}{$\begin{array}{l}\text { A 67-year-old male is brought to the GP } \\
\text { by his family because they are concerned } \\
\text { about his memory. They report that } \\
\text { he is continuously losing objects and } \\
\text { forgetting names and dates. The patient } \\
\text { acknowledges that he has had some } \\
\text { difficulty with his memory. On physical } \\
\text { examination he is noted to have a broad- } \\
\text { based unsteady gait. }\end{array}$} & $\begin{array}{l}\text { If you were } \\
\text { thinking of: }\end{array}$ & $\begin{array}{l}\text { And then you } \\
\text { find: }\end{array}$ & \multicolumn{5}{|c|}{ This management becomes: } \\
\hline & $\begin{array}{l}\text { Trialling } \\
\text { an SSRI }\end{array}$ & $\begin{array}{l}\text { During cognitive } \\
\text { testing, he } \\
\text { refuses to } \\
\text { to engage, } \\
\text { simply stating } \\
\text { "I can't" }\end{array}$ & $\begin{array}{l}\text { Much less } \\
\text { appropriate }\end{array}$ & $\begin{array}{l}\text { Slightly less } \\
\text { appropriate }\end{array}$ & $\begin{array}{c}\text { Neither more } \\
\text { nor less } \\
\text { appropriate }\end{array}$ & $\begin{array}{l}\text { Slightly more } \\
\text { appropriate }\end{array}$ & $\begin{array}{l}\text { Much more } \\
\text { appropriate }\end{array}$ \\
\hline
\end{tabular}


An important educational consequence of introducing any new assessment tool into a curriculum is the impact it may have on learning and teaching practices. Several studies have examined the consequences of SCTs, primarily in qualified doctors. Such studies have shown that short, workshop-style discussions involving SCTs can improve outcomes on short-term post-intervention assessments (Labelle et al., 2004; Petrella \& Davis, 2007). However, further studies examining the longer-term educational consequences of SCTs are still required. For instance, there has been limited use of SCTs in medical schools. The influence of SCTs on students' study and preparation for examinations will be examined in this project and referred to as "students' study approaches" (or just "study approaches").

Information regarding medical student perceptions of the authenticity and means of improvement of delivery of SCTs is also sparse. However, acceptability of a continuing professional development resource using online SCTs has been assessed in postgraduate cardiology and pediatrics (Hornos et al., 2013). The SCTs were received favourably, with strongly positive responses to questions regarding usefulness to clinical practice and development of clinical reasoning skills (Hornos et al., 2013). Previously, one study reported on the acceptability of SCTs to medical students, finding that the question style was generally accepted as representative of "real-life". Opinions were more mixed regarding whether it would be useful as a means of evaluation in future (Duggan \& Charlin, 2012). The aspect of acceptability that will be examined in this study relates particularly to the use of SCTs as a means of assessment rather than as a teaching/ learning tool.

This study was designed to gather information intended to address gaps in the literature pertaining to evidence of the educational consequences and acceptability of script concordance testing. The outcomes are compared to those of multiple-choice questions (MCQs), which are currently used widely as the gold-standard of written medical assessment. The study's specific aims were to: (a) examine student perceptions of SCT questions (regarding the acceptability of SCTs) and (b) examine how students would modify their learning methods to improve their future performance on SCTs (vs. MCQs) (examining the educational consequences of SCTs).

\section{Methods}

This study involved a practice examination using SCT and MCQ questions followed by a survey.

\section{Participants and recruitment}

The study participants were students in years 4 and 5 of the University of Adelaide Bachelor of Medicine and Bachelor of Surgery program (6-year undergraduate degree). These cohorts had previously completed SCTs in summative university assessments for the previous one (year 4 students) or two (year 5 students) years. During the course of their degree, these students had received instruction on how to complete SCTs, including during exam briefings and practice examinations. Previous instruction included statements such as: "For each question, you need to look at the proposed 
diagnosis, examination, investigation or treatment (in the first column) and then consider the impact that the additional information (given in the second column) has on how appropriate or useful the diagnosis/examination/investigation/treatment is". Given the students' previous experience with SCTs, for this project, no further instructions regarding the completion of SCTs were given prior to the examination. Following completion of the examination and survey, students who agreed to participate in the research were eligible to enter a prize draw for gift vouchers.

\section{Practice examination}

The practice examination was anonymous, online (administered on Qualtrics.com) and voluntary. All participants completed the examination under test conditions in a single testing centre. The exam was comprised of 40 SCTs and 40 MCQs, which were matched for content. Matched SCTs and MCQs both addressed the diagnosis, investigation or management of a particular presentation or condition. For example, one MCQ and one SCT assessed aspects of the management of different causes of pericarditis. To prevent cross-cueing, participants were informed of the pairing of question content prior to the examination. Students were informed that, although matched, answers to paired questions would not inherently be the same or different from the counterpart paired question encountered in the examination. Questions were presented in a random order to each student. Questions covered topics from all clinical specialty areas. The practice examination was administered in mid-October, approximately 3 weeks prior to summative end-of-year examinations.

In regard to question structure, the MCQs had a stem followed by five options. Students were required to select the single best answer. For examples of SCTs, see Table 1. All SCTs were scored by a panel of $\geq 10$ senior medical students (who had completed their final examinations) and junior doctors. This was considered reasonable, as previous research has shown that junior doctors can serve as appropriate panellists for SCT development (Duggan \& Charlin, 2016).

\section{Survey}

Survey questions were presented either as a series of statements with 6-point Likert-type scales, ranging from very strongly disagree through to very strongly agree, or as opentext questions to which students could type answers. These survey questions were then administered on the same online platform as the practice examination.

Survey questions were derived from and based upon small group discussions with students and were piloted on students prior to the examination and survey distribution.

\section{Analysis}

Statistical analysis was conducted using Rstudio (Version 1.0.153, 2017). Responses to Likert-type questions were allocated a score: 1 for very strongly disagree through to 6 for very strongly agree. The Likert-type responses were then analysed using parametric statistics. The rationale behind the use of parametric statistics to assess 
Likert-type responses has been reviewed previously (Norman, 2010; Sullivan \& Artino, 2013). Student responses regarding how they would prepare for an SCT versus an MCQ were evaluated using paired t-tests. A Bonferroni correction was conducted to enable multiple comparisons (alpha $=0.006$ ). Open-text responses were analysed using thematic analysis.

\section{Ethical approval}

Ethics approval was granted for this project by the University of Adelaide Ethics Committee (H-2017-090).

\section{Results}

Out of a class size of 329, 260 year 4 and 5 students registered to complete the practice exam and participate in the project. Of the students who registered, $211(81.2 \%)$ completed both the practice examination and survey ( $64.1 \%$ of the total cohort).

\section{Acceptability: Student perception of SCTs-Likert-type questions}

Students largely agreed that SCTs are a valid test of clinical reasoning; $60.8 \%$ of respondents either agreed, strongly agreed or very strongly agreed with this statement. The majority of students $(57.5 \%)$ also reported feeling confident (agree, strongly agree or very strongly agree) that they understand how to answer SCTs. However, $42.5 \%$ of students reported that they did not feel that they were confident that they understand how to answer SCTs.

Half of the students disagreed that SCTs were an accurate representation of their ability to diagnose $(51.5 \%)$, or to develop management plans (56.1\%), choosing disagree, strongly disagree or very strongly disagree. However, despite these apparently prevalent negative attitudes, half of the students (51.2\%) reported that they agreed (agree, strongly agree or very strongly agree) that SCTs are a more accurate representation of clinical practice than MCQs.

\section{Acceptability: Student perception of SCTs-Open-ended question}

In response to an open-ended question regarding how SCTs could be altered or administered in a more effective fashion, the most common themes reported were greater instruction regarding a few key aspects of SCT technique and being given an opportunity to provide a written explanation to their answers. Students also expressed desire for instruction regarding three key issues relating to SCTs.

First, many expressed confusion as to how to answer a question when the second piece of information provided ("and then you find ...") supports an alternative diagnosis to the one being considered but is not inherently mutually exclusive with the presented diagnosis. One student described this particularly well, with an example: 


\section{SCT STUDENT PERCEPTION AND STUDY APPROACHES}

If you are thinking $M I$ and you find there is a positive lipase, does this a) not affect the likelihood that the patient is having an $M I$ as there is still strong clinical features of $M I$ and the points are mutually exclusive [or] b) indicate that they likely have pancreatitis and therefore the MI type symptoms are likely caused by this, making MI much less likely. (Year 4, student 1)

Second, students expressed desire for clarification as to how examinees are expected to approach a new piece of clinical information in light of a given hypothesis they feel is already highly probable. In other words, should they answer "neither more nor less" (i.e., the 0 -response), since the new piece of information does not alter the likelihood of an already-likely hypothesis or "more likely", since the new information further supports it? For example, one student stated:

Often it's ambiguous as to what the answers actually mean; for example, if I thought the initial proposal was already very appropriate, and with the extra bit of information remained very appropriate, do I put that it's even more so appropriate or no change? (Year 5, student 2)

Third, students expressed a desire for further instruction regarding how to discern between "slightly" and "much" more/less likely options. An example of one such desire was:

Having clearer instructions as to what makes something "much more" vs "slightly more" appropriate would be helpful. It's difficult to know in each situation where to draw the line. (Year 4, student 3)

Students often expressed the desire to explain their answers. It was commonly reported that the opportunity to explain their reasoning would help to allay concerns regarding not being able to fairly demonstrate their knowledge and reasoning. For example, multiple students described sentiments such as:

I like ... writing out reasons for them [SCTS]; it would help the markers understand what we were thinking and potentially could aid us in passing the year. (Year 5, student 4)

Students proposed modifications to the SCT exam format, including a space to provide written explanations beneath SCTs and a variety of question styles in summative assessments, such as short answer questions. Although the question related to SCTs, multiple students proposed similar alterations to MCQs, including adding a written component to each question and conducting exams with multiple question styles.

\section{Educational consequences of SCTs (vs MCQs)_Likert-type questions}

There were several significant differences in how students described how they would prepare for a future SCT exam, relative to how they would prepare for an MCQ exam. Students reported that they would be more likely to use textbooks to review for an MCQ exam relative to an SCT exam $(p<0.001)$ (see Figure 1$)$. Similarly, students reported that they would be more likely to learn from websites (such as UpToDate or 


\section{Student Response to Likelihood of Exam Preparation Modifications in Light of Theoretical SCT/MCQ Exam}

$\begin{array}{llllllllll}0 \% & 10 \% & 20 \% & 30 \% & 40 \% & 50 \% & 60 \% & 70 \% & 80 \% & 90 \%\end{array}$

* - SCT - Learning from textbooks

- MCQ - Learning from textbooks

* _ SCT - Learning from websites

- MCQ - Learning from websites

SCT - Learning management algorithms and guidelines

MCQ - Learning management algorithms and guidelines

SCT - Learning from ward-based patient encounters

MCO - Learning from ward-based patient encounters

SCT - Learning from clinic-based patient encounters

MCQ - Learning from clinic-based patient encounters

SCT - Studying with groups of medical students

MCQ - Studying with groups of medical students

* _ SCT - Learning from allied health professionals

— MCQ - Learning from allied health professionals

응

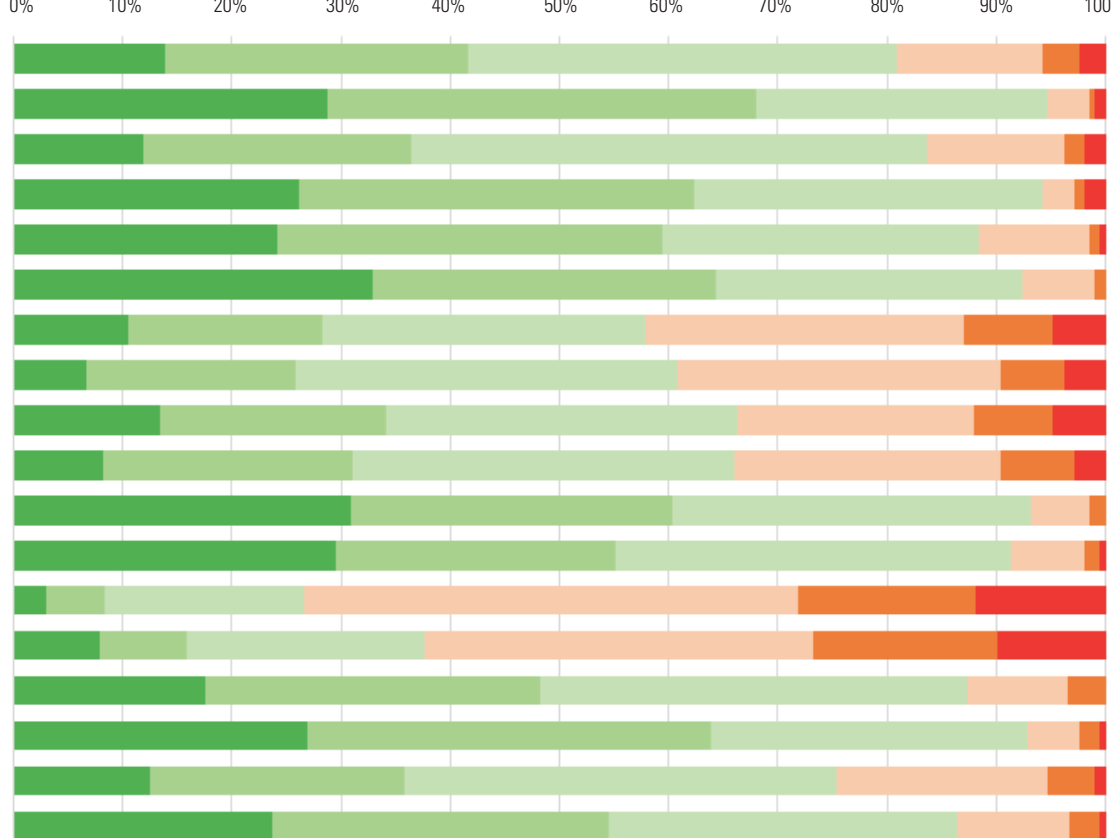

* _ SCT - Learning about uncommon presentations of common diseases

— MCQ - Learning about uncommon presentations of common diseases

Very strongly agree $\quad$ Strongly agree

Agree Disagree

Strongly disagree

Very strongly disagree

${ }^{*} p<0.001$

Figure 1. Results from a survey investigating student response to likelihood of exam preparation modifications in light of theoretical SCT/MCQ exam. 
Medscape) and allied health professionals to prepare for an MCQ exam than for an SCT exam $(p<0.001)$. Regarding content, students more often reported that they would study uncommon presentations of common conditions for an MCQ exam as opposed to an SCT exam $(p<0.001)$. The same was true regarding studying classical presentations of rare conditions $(p<0.001)$. There were no significant differences in reported study strategy regarding learning treatment guidelines, learning from wardbased or clinic-based patient encounters, learning from allied health professionals or studying in a group with other medical students.

Student opinion was sought regarding the usefulness of a series of interventions proposed to facilitate preparation for an SCT examination. The most positivelyreceived suggestion was receiving feedback on individual questions (with answers) after exams; 156 respondents (75\%) "very strongly" agreed that receiving such feedback would help them to prepare for SCT examinations. Specialty-based feedback (53\% very strongly agreed), further hospital-based small-group learning sessions (48\% very strongly agreed) and a greater emphasis on management in the setting of diagnostic uncertainty (39\% very strongly agreed) were all also strongly supported. Proposed interventions related only to SCTs, and hence responses to similar questions regarding MCQs are not available.

\section{Educational consequences of SCTs (vs MCQs)—Open-ended question}

There were three key themes that arose when students were provided with an opentext question asking them to describe which intervention they thought would most assist them to be successful in completing future SCTs. The most commonly suggested intervention was further in-person teaching of medical content by consultants who form the SCT scoring panels. It was put forward that this would be most beneficial because it would indicate local practice preferences in contrast with international/overseas textbooks and websites. For example, one student felt they would benefit from:

[More of] a local consultant or doctor point of view, as the ultimate answer is all defined by the expert scoring panels and not textbooks. (Year 5, student 5)

Further instruction regarding SCT technique by consultants who form the SCT scoring panels was also frequently suggested. Finally, consistent with the results discussed in the paragraph above, it was also often suggested that further practice SCTs, with answers, would enable better preparation in future. For example, students described that they would benefit from "access to more practice questions to understand the style of question/thinking expected" or a "massive SCT bank with answers". 


\section{Discussion}

In this study, we sought to examine the perceptions of medical students with prior experience of SCT and MCQ-type assessments regarding the educational consequences and acceptability of these assessment methodologies, including how these influenced their approach to learning and their confidence in approaching the question format. Our results indicate that students thought they would prepare for MCQ and SCT examinations differently. Such results suggest that SCTs may be an important component of formative and, potentially, summative assessments.

Students are more likely to prioritise textbooks and websites when preparing for an MCQ examination. Conversely, students express that in-person teaching of medical content by local consultants who are involved in the SCT generation process would best help them to prepare for future SCT examinations. This preference may indicate that in-person teaching helps students to better develop complex illness scripts than if they solely rely on what is covered in a textbook or website. Given that such unwritten illness scripts may be viewed as a component of the "hidden curriculum", this rationale would support the use of SCTs in assessments as a means to facilitate learning. An alternative interpretation is that students might prefer gaining direct exposure to test content rather than learning more broadly. This outcome would be a negative educational consequence. In addition, there are practical implications of implementing this preference, including pre-existing multiple time-demands on such consultants. Even so, these results suggest that employing a combination of SCTs and MCQs may encourage the use of a broader selection of study strategies, compared with either question style alone.

While the majority of students accept that SCTs are a good test of clinical reasoning and are representative of clinical practice, many express concerns regarding their understanding of how to answer certain aspects of SCTs. Students thought that SCTs could be delivered in a more effective fashion if instruction were provided regarding key elements of SCT technique and if an opportunity was afforded to provide written explanations of their reasoning. However, the marking of written explanations could increase the required resources associated with running an examination including SCTs.

The reason that student study approaches differ between MCQs and SCTs is uncertain. It has been shown that performance on SCTs improves with increased clinical experience (Charlin, Brailovsky, Leduc, \& Blouin, 1998). Students may place more emphasis on learning from senior clinicians and less emphasis on learning from textbased sources (such as books and websites) when reviewing for SCTs because they feel it is a more effective means to improve understanding of management strategies based upon locally-relevant clinical experience. It would seem reasonable that, to improve clinical experience, students would seek out clinical experience in ward and clinicbased patient interactions. One possible explanation for this finding is that students may feel that they can learn from consultants' experience more efficiently through direct teaching than from participating in/observing the consultants' clinical practice. 
Students highlighted several areas in which they felt they would benefit from further instruction regarding how to answer SCTs. One area involved the issue of how to answer a question about an investigation or treatment that a student feels is already absolutely indicated prior to receiving the new piece of information. It has previously been stated that SCTs in which the initial hypothesis has an overly high pre-test probability should be discarded since there is insufficient uncertainty for it to be an effective question (Lubarsky, Gagnon, \& Charlin, 2011b). Therefore, theoretically, such a situation should not arise in an SCT exam. Accordingly, if a student finds themselves in such a position, it indicates that either (a) a question writing error has occurred, with the inclusion of a question that should have been discarded or (b) the student has insufficient understanding of the clinical scenario to be aware that the investigation/treatment is not, in fact, already absolutely indicated.

The findings of this study have several practical implications for medical educators. When providing instruction regarding SCTs, as a part of their implementation, educators should endeavour to have formative examples on which students can practice, complete with answers. In particular, it may be beneficial to have instruction regarding, and examples demonstrating, the three key issues highlighted by participants in this study as potentially causing confusion.

One limitation of this project is that it was conducted at a single site. It is possible that students at other centres may not have a similar experience with SCTs. The assessment of the consequences of the SCT examination format was limited to asking students how they predicted they would study for a future MCQ or SCT examination. It is possible that actual study patterns may differ from those predicted by the students. Also, to protect anonymity, in this examination, demographic details of participants were not collected. Finally, the panel used to score the exams could be considered sub-optimal, given a previous finding that at least 10-15 panellists are required for an SCT to hold adequate reliability (Gagnon, Charlin, Coletti, Sauve, \& van der Vleuten, 2005).

Accordingly, future research projects aiming to examine the educational consequences and acceptability of SCTs for medical students should endeavour to link SCT participation with observed behaviour modification in addition to predicted behaviour modification.

\section{Conclusions}

This study indicates that SCTs have educational consequences different from MCQs. This finding may support the use of SCTs, in addition to MCQs, in medical school assessments. The majority of students accept that SCTs are a good test of clinical reasoning and are representative of clinical practice. However, many express concerns regarding their understanding of how to answer certain aspects of SCTs. This study suggests possible interventions that may help to assuage these concerns, including more in-person teaching, particularly from individuals who compose SCT scoring panels, and practice SCTs with answers. Further research into the educational consequences 
SCT STUDENT PERCEPTION AND STUDY APPROACHES

of SCTs, and how these consequences may differ from those of other methods of assessment, is warranted.

\section{Acknowledgements}

The authors would like to thank the volunteers who formed the scoring panel for the SCTs used in this study and the students who participated in the study.

\section{Funding and conflict of interest statement}

The authors have no conflicts of interest to declare. This research did not receive any specific grant from funding agencies in the public, commercial or not-for-profit sectors.

\section{References}

Charlin, B., Boshuizen, H. P., Custers, E. J., \& Feltovich, P. J. (2007). Scripts and clinical reasoning. Medical Education, 41(12), 1178-1184. doi:10.1111/j.13652923.2007.02924.x

Charlin, B., Brailovsky, C., Leduc, C., \& Blouin, D. (1998). The Diagnosis Script Questionnaire: A new tool to assess a specific dimension of clinical competence. Advances in Health Sciences Education, 3(1), 51-58.

Charlin, B., Gagnon, R., Pelletier, J., Coletti, M., Abi-Rizk, G., Nasr, C., . . . van der Vleuten, C. (2006). Assessment of clinical reasoning in the context of uncertainty: The effect of variability within the reference panel. Medical Education, 40(9), 848-854. doi:10.1111/j.1365-2929.2006.02541.x

Charlin, B., Roy, L., Brailovsky, C., Goulet, F., \& van der Vleuten, C. (2000). The script concordance test: A tool to assess the reflective clinician. Teaching and Learning in Medicine, 12(4), 189-195. doi:10.1207/S15328015TLM1204_5

Charlin, B., \& van der Vleuten, C. (2004). Standardized assessment of reasoning in contexts of uncertainty: The script concordance approach. Evaluation \& the Health Professions, 27(3), 304-319. doi:10.1177/0163278704267043

Cook, D. A., Zendejas, B., Hamstra, S. J., Hatala, R., \& Brydges, R. (2014). What counts as validity evidence? Examples and prevalence in a systematic review of simulation-based assessment. Advances in Health Sciences Education: Theory and Practice, 19(2), 233-250. doi:10.1007/s10459-013-9458-4

Duggan, P., \& Charlin, B. (2012). Summative assessment of 5 th year medical students' clinical reasoning by script concordance test: Requirements and challenges. BMC Medical Education, 12(1).

Duggan, P., \& Charlin, B. (2016). Introducing recent medical graduates as members of script concordance test expert reference panels: What impact? $A M E E$ MedEdPublish. doi:10.15694/mep.2016.000060

Fournier, J. P., Demeester, A., \& Charlin, B. (2008). Script concordance tests: Guidelines for construction. BMC Medical Informatics and Decision Making, 8, 18. doi:10.1186/1472-6947-8-18 
Gagnon, R., Charlin, B., Coletti, M., Sauve, E., \& van der Vleuten, C. (2005). Assessment in the context of uncertainty: How many members are needed on the panel of reference of a script concordance test? Medical Education, 39(3), 284291. doi:10.1111/j.1365-2929.2005.02092.x

Hornos, E. H., Pleguezuelos, E. M., Brailovsky, C. A., Harillo, L. D., Dory, V., \& Charlin, B. (2013). The practicum script concordance test: An online continuing professional development format to foster reflection on clinical practice. Journal of Continuing Education in the Health Professions, 33(1), 59-66. doi:10.1002/ chp. 21166

Labelle, M., Beaulieu, M., Paquette, D., Fournier, C., Bessette, L., Choquette, D., ... Thivierge, R. L. (2004). An integrated approach to improving appropriate use of anti-inflammatory medication in the treatment of osteoarthritis in Quebec (Canada): The CURATA model. Medical Teacher, 26(5), 463-470. doi:10.1080/0142159042000218669

Lubarsky, S., Charlin, B., Cook, D. A., Chalk, C., \& van der Vleuten, C. P. (2011). Script concordance testing: A review of published validity evidence. Medical Education, 45(4), 329-338. doi:10.1111/j.1365-2923.2010.03863.x

Lubarsky, S., Dory, V., Audétat, M., Custers, E., \& Charlin, B. (2015). Using script theory to cultivate illness script formation and clinical reasoning in health professions education. Canadian Medical Education, 6(2), 61-70.

Lubarsky, S., Dory, V., Duggan, P., Gagnon, R., \& Charlin, B. (2013). Script concordance testing: From theory to practice: AMEE guide no. 75. Medical Teacher, 35(3), 184-193. doi:10.3109/0142159X.2013.760036

Lubarsky, S., Gagnon, R., \& Charlin, B. (2011). Script concordance test item response process: The argument for probability versus typicality. Advances in Health Sciences Education, 17(1), 11-13. doi:10.1007/s10459-011-9338-8

Messick, S. (1989). Validity. In R. L. Linn (Ed.), Educational measurement (3rd ed.) (pp. 13-104). New York, NY: American Council on Education and Macmillan.

Norman, G. (2010). Likert scales, levels of measurement and the "laws" of statistics. Advances in Health Sciences Education: Theory and Practice, 15(5), 625-632. doi:10.1007/s10459-010-9222-y

Petrella, R. J., \& Davis, P. (2007). Improving management of musculoskeletal disorders in primary care: The Joint Adventures Program. Clinical Rheumatology, 26(7), 1061-1066. doi:10.1007/s10067-006-0446-4

Sullivan, G. M., \& Artino, A. R., Jr. (2013). Analyzing and interpreting data from Likert-type scales. Journal of Graduate Medical Education, 5(4), 541-542. doi:10.4300/JGME-5-4-18

van der Vleuten, C. (1996). The assessment of professional competence:

Developments, research and practical implications. Advances in Health Sciences Education, 1(1), 41-67. 